\title{
Traducir el policial: Aproximaciones al género en La traducción (1998), de Pablo De Santis
}

\section{Translating Detective Fiction: Approaches to the Genre in La traducción (1998) by Pablo De Santis}

\section{HERNÁN MALTZ}

Instituto de Filología y Literaturas Hispánicas Dr. Amado Alonso

Universidad de Buenos Aires

25 de mayo 217, primer piso.

Buenos Aires, C1002ABE. Argentina

h.maltz@conicet.gov.ar

Orcid ID 0000-0003-2274-1873

Resumen: Los dispersos y acotados estudios sobre la obra de Pablo De Santis tienden a considerar que sus textos están atravesados por el género policial, pero al mismo tiempo no hay producciones que justifiquen de manera sistemática dicha afirmación. Así, en este trabajo nos centramos en La traducción (publicada originalmente en 1998 y finalista del Premio Planeta en 1997), con la intención de analizar las modalidades en que esta novela se acerca y trabaja con distintos aspectos del amplio género policial. En primer lugar, analizamos la doble delimitación espacial y la presencia de una lengua extranjera como elementos que nos permiten asociar la novela con la vertiente clásica del policial. Luego nos centramos en el problema de la nacionalización de género y la figura del comisario, factores que permiten asociar la ficción con la tradición local del género. También nos abocamos a la historia de los lobos marinos, paralela a la trama principal, y en ella encontramos aspectos que traen a cuenta la novela negra. Por último, en base a las distintas cuestiones señaladas, indicamos los usos posibles del concepto de género. Con la sumatoria de estos elementos, veremos que La traducción manifiesta un conocimiento y un trabajo con el género policial muy precisos por parte de De Santis, aun en el caso de esta novela de cuyo carácter policial el propio autor reniega.

Palabras clave: Pablo De Santis. Policial clásico. Género negro. Policial argentino. Género. 
Abstract: The scattered and limited studies on the work of Pablo De Santis tend to consider that his texts are crossed by the detective genre, but at the same time there are no productions justifying this claim. Therefore, in this paper I focus on La traducción (originally published in 1998 and finalist of the Premio Planeta in 1997), with the intention of analyzing the ways in which this novel uses and works with different aspects of the detective genre. First, I analyze the double spatial delimitation and the presence of a foreign language as elements that allow us to associate La traducción with the classic detective fiction. Then I focus on the problem of the nationalization of detective fiction and the figure of the superintendent, two factors that allow us to as- sociate the novel with the local tradition of detective fiction. I also analyze the history of sea lions, parallel to the main plot, in which I find ways to set a link with the hard-boiled fiction. Finally, based on the various issues identified, I finish the paper with a reflection on the possible uses of the concept of genre. With the sum of these elements, I see that La traducción expresses a deep knowledge and precise work of De Santis with the detective genre, even though the author denies its character of detective fiction.

Keywords: Pablo De Santis. Classic Detective Fiction. Hard-boiled. Argentinian Detective Fiction. Genre.

\section{INTRODUCCIÓN}

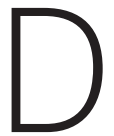

istintos trabajos mencionan la dirección policial de la narrativa de Pablo De Santis: Saítta, Guiñazú, Gamerro, Néspolo, Konstantinova (2006; 2010), Wieser y Jacovkis. Particularmente, tanto Narváez como Requeni coinciden en pensar una posible tríada policial a partir de una serie de libros publicados de manera consecutiva en 1998: Páginas mezcladas, Filosofía y Letras y La traducción (más tarde, a este grupo se sumaron dos novelas que constituyen otro núcleo policial en el conjunto de la obra del escritor: El enigma de París y Crímenes y jardines, de 2007 y 2013 respectivamente). Sin embargo, los estudios citados no suelen justificar la adscripción de los textos de De Santis al género policial: la mayor parte de las veces la clasificación se reduce a una mención y no hay argumentación alguna. ${ }^{1}$ Por lo tanto, en este escrito pretendemos desarrollar algunas líneas que muestren las participaciones y las evocaciones del género en la narrativa de De Santis, a partir de una novela en particular: La traducción. Su historia se inicia con un congreso sobre traducción que se lleva a cabo en la localidad balnearia de Puerto Esfinge. Sin embargo, el evento resulta tomado por una misteriosa serie de muertes de traductores -serie a la que, paralelamente, se suma otra sucesión de muertes, pero de lobos marinos-.

1. Esto se debe a que la mayoría de los trabajos mencionados no tiene a De Santis como su centro de estudio. La principal excepción al reparo que planteamos son los trabajos de Konstantinova (2006; 2010), que sí justifican la adscripción de De Santis -y, particularmente, de La traducción y Filosofía y Letras- a una variante específica de la literatura policial: la metaphysical detective fiction. 
EL LUGAR (DEL) CLÁSICO: LA PEQUEÑA LOCALIDAD Y EL HOTEL COMO DOS FORMAS DE AISLAMIENTO

Suele mencionarse el cuarto cerrado como un motivo que acompaña al género policial desde sus orígenes (Rivera 1996,103), con el ejemplo fundacional de "The Murders in the Rue Morgue" (1841) de Edgar Allan Poe. ${ }^{2}$ Las historias que suceden en una localidad chica y que involucran a una pequeña comunidad también son tratadas en la vertiente clásica del policial: en este caso hallamos, otra vez en la obra de Poe, un relato inaugural, con el cuento "Thou Art the Man" (1844). Asimismo, el hotel posee un rol paradigmático en el desarrollo del género, pues permite delimitar un aislamiento y por ende una historia con pocos personajes -e incluso desconocidos entre sí, a diferencia de la historia en una comunidad cerrada-. ${ }^{3}$ Algunos ejemplos de policiales clásicos en hoteles los tenemos con Agatha Christie: Evil Under the Sun (1941), con Poirot como detective, o A Caribbean Mystery (1964) y At Bertram's Hotel (1965), que tienen como protagonista a Miss Marple. Otros casos pueden ser The Chinese Orange Mystery (1934), de Ellery Queen, ${ }^{4}$ o Too Many Cooks (1938), de Rex Stout. En un nivel local, un ejemplo significativo para la tradición policial argentina es el Hôtel du Nord del cuento "La muerte y la brújula" de Jorge Luis Borges. De modo que, en el marco de este linaje genérico de ámbitos cerrados y apartados, podemos analizar el espacio fictivo de La traducción. En la novela distinguimos, de hecho, un doble aislamiento.

En primer lugar, la historia se desarrolla en una localidad ignota, Puerto Esfinge, "[u]na ciudad fantasma de la costa argentina", como se sostiene en la contratapa del libro. " "No sabía que existía" (De Santis 1998, 20), dice Miguel De Blast, el traductor y protagonista de la historia, a Rina, una colega italiana, mientras viajan en combi hacia allí. De Blast cuenta y juzga lo que

2. Cook es más categórico y concluye su estudio sobre la ficción policial de cuarto cerrado con la afirmación de que dicho motivo es menos una forma que una esencia del género (172). Si bien esta sentencia resulta un tanto exagerada, su libro no deja de ser pertinente en tanto analiza detalladamente este significativo motivo en distintos autores (Poe, Chesterton, Borges y otros).

3. Kracauer aborda el estudio del vestíbulo del hotel en las novelas policiales y hace énfasis en el carácter impersonal y vacío de este ámbito (59-71).

4. Recordemos que Ellery Queen era el seudónimo con el que trabajaba una pareja de escritores: Frederick Dannay y Manfred Bennington Lee.

5. Desde luego, el nombre de la localidad nos permite trazar una conexión con Edipo Rey, la Esfinge deTebas y el enigma que esta plantea. Por otra parte, en el marco global de la narrativa de De Santis, Puerto Esfinge puede ser pensada en vínculo con otras ciudades inventadas por el autor y que este ubica en suelo argentino, como El Botánico en Las plantas carnívoras (1995) o Los Álamos en Los anticuarios (2010). 
dicen otras personas que miran por las ventanas del transporte: "Los otros pasajeros comentaban el paisaje, es decir, el no-paisaje. A los costados del camino no había nada; ni una sola construcción en ochenta kilómetros" (20). En la conversación que sostienen, Rina saca un plano que sirve a De Blast para reflexionar sobre la inversión que percibe en la relación entre mapa y territorio: "Los mapas son una versión abstracta del paisaje; pero en aquel viaje las cosas ocurrían al revés, y el paisaje era una versión abstracta del mapa". Rina le señala a su colega un punto en el mapa, pero De Blast no lo encuentra. ${ }^{6} \mathrm{Y}$, al carácter abstracto percibido en la ruta, se suma la imagen de desolación que impera cuando la combi llega a Puerto Esfinge:

Pasamos primero junto a un cementerio con rejas de hierro, encerrado entre paredes grises, y luego junto a un faro que parecía abandonado. Lo rodeaba un alambrado que en un sector se había derrumbado sobre el pasto.

El viento sacudía la combi. El mar, gris y picado, había levantado en la playa una franja de algas muertas, que en algunos puntos tomaba la consistencia de un largo muro de podredumbre. (21)

Estas imágenes se repiten a lo largo de la novela: tanto las construcciones humanas (el faro, la mina de carbón de la Salina Negra) como la propia naturaleza (las algas, los huesos de pájaros) presentan signos de decadencia y descomposición. En el hotel abandonado y en la sucesión de lobos marinos muertos apreciamos, respectivamente, el cenit de estas cuestiones, aunque la serie de lobos marinos muertos resulta ligada a la actividad del hombre, como leemos hacia el final de la novela.

En segundo lugar, en medio de la desolación de Puerto Esfinge, tenemos a su vez otro aislamiento, dado por el hotel donde se desarrolla el congreso sobre traducción. El propio emplazamiento del hotel lo deja apartado del aislamiento que, per se, representa Puerto Esfinge: "La combi se detuvo frente al hotel. A un kilómetro y medio de distancia, empezaban las primeras

6. En esa cualidad que marca al territorio de Puerto Esfinge como algo tan abstracto que casi pierde entidad, podemos trazar un paralelismo con el espacio del castillo gótico: "The castle has not to do with the map, and with the failure of the map; it figures loss of direction, the impossibility of imposing one's own sense of place on an alien world" (Punter/Byron 262). Así, ese "no-paisaje" de Puerto Esfinge también nos sugiere la idea de la pérdida de la ubicación en el mundo. 
casas" (21). La descripción del hotel que nos brinda De Blast da cuenta de un edificio abandonado en dos sentidos: si la cita anterior resalta su alejamiento, las siguientes palabras del traductor remarcan su carácter parcialmente vacío:

El hotel era totalmente desproporcionado en comparación con Puerto Esfinge. Era el centro de un gran complejo turístico que no había llegado a existir. Estaba construido en dos cuerpos que se abrían en ángulo sobre la costa. Una mitad estaba terminada y empezaba a decaer; la otra mitad no tenía puertas, ni ventanas ni mampostería. Un cartel inmenso anunciaba la continuación de las obras, pero no se veían maquinarias ni obreros ni materiales de construcción. Sobre la entrada, leí en letras plateadas Hotel Internacional del Faro; arriba colgaban unas banderitas deshilachadas y descoloridas. (21)

Más allá de las condiciones decadentes del hotel, este espacio reducido permite limitar el número de personajes. Y, cuando comienzan las muertes, también el número de sospechosos. Así, la trama de La traducción se estructura a partir de una serie de muertes de traductores diseminadas a lo largo de la historia. ${ }^{7}$ Pero el carácter policial de la novela no viene dado por la sucesión en sí, sino por el enigmático interrogante que ella engendra: ¿cómo y por qué se producen esas muertes? El misterio se origina a partir de "una lengua extranjera" (así se llama, de hecho, la segunda parte del libro). Ximena, la joven periodista que halla el cadáver de Valner, el primer muerto de la novela, cuenta cómo llega a ubicarlo a partir de seguir las resonancias de una voz cuyo idioma no puede definir: "Ni inglés, ni francés ni ningún idioma que yo pueda identificar" (57). Resulta pertinente, entonces, si trazamos una analogía con el ya citado relato fundacional de la literatura policial "The Murders in the Rue Morgue" de Edgar Allan Poe. En dicho cuento tenemos una serie de testimonios entrecruzados en torno a las dos voces que provienen desde

7. La estructura de un relato organizado en torno a una serie de muertes es un leitmotiv en la narrativa de De Santis. Dentro de esta amplia caracterización, podemos inscribir La traducción (1998) en un núcleo conformado por otras tres novelas: Filosofía y Letras (1998), El teatro de la memoria (2000) y El calígrafo de Voltaire (2002). Estas cuatro ficciones pueden constituir una unidad en el marco de la obra de De Santis por varios motivos: su secuencialidad en la escritura y publicación; su extensión de 180 a 220 páginas; su estructura de la narración dividida en tres partes (salvo por La traducción, que tiene cuatro); el empleo de una trama basada en torno a una sucesión de muertes, con protagonistas masculinos e historias amorosas frustradas; y el uso de motivos y temas comunes (reflexiones sobre la lengua, la escritura, los libros, el espacio urbano, etcétera). 
el cuarto cerrado donde se cometen los crímenes: todos afirman que una voz áspera habla en francés, pero ninguno coincide respecto al idioma que le corresponde a la extraña voz aguda. Sin embargo, como sostiene el detective Dupin, "la peculiaridad es, no que no se pusieran de acuerdo, sino que un italiano, un inglés, un español, un holandés y un francés intentaron describirla; todos hablaron de un extranjero. Todos estaban seguros de que no era la voz de un compatriota" (Poe 493; cursiva original). En este sentido específico, en el intento de identificar la procedencia de una voz extraña, el cuento de Poe cifra el enigma en una voz extranjera. Así, podemos colocar a La traducción en una línea sucesoria con este relato fundacional de la literatura policial. ${ }^{8} \mathrm{Y}$, en cierta forma, la novela de De Santis profundiza el papel de la lengua extranjera, pues esta no solo se sitúa en el centro del enigma sino que también protagoniza la serie de muertes. ${ }^{9}$

TRADUCIR EL POLICIAL: HISTORIA PARTICULAR DE UN PROBLEMA "NACIONAL"

En el primer apartado consignamos dos elementos que nos permiten establecer un vínculo con el policial de enigma o clásico: la delimitación de un ámbito cerrado y la presencia de una lengua desconocida. Sin embargo, en $L a$ traducción hallamos aspectos que marcan otro sentido particular de lo policial, ligado a la inserción del género en la Argentina. La intención de adaptar, trasponer, traducir fórmulas genéricas estaba en las preocupaciones de los escritores desde mediados del siglo XX, e incluso antes. ${ }^{10}$ Pensemos en la "No-

8. Konstantinova $(2006,202-03)$ ya había señalado que De Santis se hace eco de Poe en La traducción, aunque la estudiosa se refiere a otro cuento fundacional, "The Purloined Letter" (1844), y a la presencia de una carta como motivo clave del relato.

9. En vista de nuestros objetivos, en este escrito analizamos el papel de la lengua con relación al género policial, aunque, en el hecho de que sea la propia lengua la que mata, tenemos un elemento que acerca la novela al género fantástico. De cualquier modo, este evento fantástico es vinculable al género policial: podemos remitirnos al argumento de Konstantinova (2006), que piensa la performatividad de la lengua asesina en relación con la variante específica de la metaphysical detective fiction. Por otra parte, La traducción tampoco es la primera novela de orientación policial en la que apreciamos el motivo de una lengua que envenena y mata; al menos dos novelas previas contienen esta idea: El maestro del juicio final (1923), de Leo Perutz, y El nombre de la rosa (1980), de Umberto Eco. De hecho, De Santis, en una entrevista, confiesa su aprecio por Perutz y sostiene la idea de que El nombre de la rosa es impensable sin el antecedente de $E l$ maestro del juicio final (Wieser 66-67).

10. En la carta al editor que precede a la primera novela policial en castellano, La buella del crimen (1877), Raúl Waleis -seudónimo de Luis V. Varela- se declara heredero de Poe y Gaboriau (Waleis 23-24). 
ticia" de Rodolfo Walsh que precede a su compilación de Diez cuentos policiales argentinos (1953); en ella afirma que, en paralelo a las que él consideraba las primeras producciones de literatura policial del país (a cargo de Bioy Casares, Borges, Castellani y Peyrou),

se ha producido un cambio en la actitud del público: se admite ya la posibilidad de que Buenos Aires sea el escenario de una aventura policial. Cambio que puede juzgarse severamente a la luz de una crítica de las costumbres, pero que refleja con más sinceridad la realidad del ambiente y ofrece saludables perspectivas a la evolución de un género para el que los escritores argentinos me parecen singularmente dotados. Buenos Aires no es ya la ciudad hostil a la novela. (Walsh 1953, 8; cursiva original)

Igualmente ilustrativa resulta la "Intención" de Velmiro Ayala Gauna en Los casos de Don Frutos Gómez (1955). En dicha nota introductoria, el escritor trae a colación el habitual pensamiento de diversos autores que "sostienen la imposibilidad del florecimiento de un género policial con ambiente y tipos netamente argentinos". Y continúa: "Para ellos el detective sólo puede moverse a gusto en las proximidades de Scotland Yard, de la Sureté o del F.B.I., teniendo como campo de acción principal a Londres, París, Nueva York o Chicago" (Ayala Gauna 43). Sin embargo, Ayala Gauna se sirve de la figura del rastreador (cita al propio Sarmiento, con el ejemplo puntual de Calíbar) para sostener que

si tal literatura no ha florecido entre nosotros, no ha sido por falta de antecedentes ni de tipos que puedan protagonizar esos relatos, ya que nuestro rastreador y, aun el vulgar hombre de campo, tenían el mismo poder de observación y un conocimiento empírico que balanceaba el caudal científico de Conan Doyle y que los hacía capaces de tan hábiles razonamientos deductivos como al morador de Baker Street. (44)

Ayala Gauna, en su apuesta literaria por el comisario Don Frutos Gómez, intenta justamente demostrar que "los cuentos de ficción policial son perfectamente posibles de desarrollar dentro de una atmósfera argentina" (45).

De nuestra parte, podemos pensar un posible diálogo que La traducción establece con tales debates de mediados del siglo XX. Nos resulta significativa la voz del no casualmente uruguayo Vázquez, que invita a De Blast a un debate sobre traducción de novelas policiales: 
-Estamos reunidos en una comisión para hablar sobre la traducción de la novela policial. ¿No quiere venir?

A Vázquez le gustaba menos conversar que ser oído, y necesitaba auditorio para sus anécdotas.

-Tengo que salir.

-Estamos discutiendo si hay que hacer hablar a los gángsters neoyorquinos en lunfardo rioplatense.

Prometí que iría, en ese tono en que se puede mentir con tranquilidad, porque se da por descontado que nadie va a creer lo que decimos. (De Santis 1998, 117-18)

En el fragmento citado hallamos una explícita tematización del problema de la nacionalización del género policial -en un aspecto específico, relativo a cómo captar y representar la oralidad proveniente de la tradición del hardboiled- $\mathrm{y}$, al mismo tiempo, notamos un indiscutible desentendimiento por parte de De Blast frente a tal problema: dice que se tiene que ir e inventa una promesa sobre su presencia en la comisión de debate. Sin embargo, cuando vuelve al hotel después de pasar un rato afuera, le pregunta al traductor uruguayo sobre el resultado de la reunión:

Me senté con Vázquez.

- ¿Cómo terminó el debate?

-Que hay que traducir solamente novelas con pistoleros sordomudos, para evitar el problema del coloquialismo. Hizo bien en no venir, me aburrí mucho.

-Creí que iba a hablar usted todo el tiempo.

-Hablé yo todo el tiempo, pero igual me aburrí. (125)

Si bien la ficción nos presenta un simple chiste, de la irónica respuesta de Vázquez también podemos desprender una conclusión: la imposibilidad de traducir policiales a una escala local. La presunta relevancia del problema de la nacionalización del género policial resulta atenuada y relativizada por algunas circunstancias: no sólo el desinterés de De Blast, sino el aburrimiento que confiesa el propio Vázquez, que simultáneamente juega con naipes al solitario. Así, distinguimos una suerte de doble movimiento con el que trabaja $\mathrm{La}$ traducción: trae a cuenta un problema específico de la historia de la literatura policial argentina, que ha merecido debates con cierta solemnidad (ejemplifi- 
cados en los fragmentos citados de Walsh y Ayala Gauna), aunque lo presenta bajo la forma de un chiste. ${ }^{11}$

Ya en una ficción previa, la novela de aprendizaje Las plantas carnívoras (1995), hallamos una sucinta pero significativa mención al problema de la nacionalización del género policial, y que podemos ubicar en sintonía con la forma chistosa de abordar dicho tema en La traducción. El protagonista, Leo, recuerda las historias policiales que les contaba el padre a él y su hermano:

Eran intrigas policiales, que protagonizaba Saturnino Reyes, un detective gaucho que vivía en Londres. Resolvía los casos apelando a su infalible astucia campera y a sus boleadoras. Recorría castillos, mansiones enormes y lagos de Escocia resolviendo crímenes cometidos en ambientes de la nobleza británica. Tenía un amigo uruguayo que lo admiraba y que siempre lo llamaba 'maestro', Walter Washington Benítez, con quien compartía la pasión por el mate. En la yerba estaba el secreto de la inteligencia y la fuerza de Saturnino Reyes. (De Santis 2006, 112)

Desde luego, el nombre, el mate y las boleadoras nos hacen pensar en una versión del discurso criollista que se manifiesta, de manera jocosa, en un segmento de la literatura policial argentina: por ejemplo, en la figura del ya mencionado Don Frutos Gómez de Ayala Gauna o en el Isidro Parodi de Borges, que podrían formar parte de un grupo de "detectives materos". ${ }^{12}$ Esto, sumado al exacerbado uruguayismo de Benítez -con su nombre "Washington"-, nos permite traer a colación la conferencia "El escritor argentino y la tradición”, en la que Borges justamente desarrolla la idea de que la argentinidad de un texto no pasa por exponer una sumatoria de elementos autóctonos: "Creo que los argentinos [...] podemos creer en la posibilidad de ser argentinos sin abundar en color local" (Borges 195-96). Además de la desbordada argentinidad de Reyes con el mate y las boleadoras, en este caso De Santis aplica el

11. Konstantinova $(2006,200-01)$ también señala que Vázquez, si bien se mantiene al margen de la trama principal, desempeña un papel importante en ella, pues en su condición de traductor provee un comentario auto-consciente sobre el estatuto de La traducción como ficción. La estudiosa cita unas palabras de Vázquez en las que apreciamos la tematización del género policial en el interior de la ficción: "Los misterios están ahí para darnos tema de conversación, no para que los solucionemos" (De Santis 1998, 126).

12. Respecto al discurso criollista, la referencia insoslayable es el estudio de Prieto. Por otra parte, además de los dos ejemplos de personajes de ficción, el nombre "Saturnino" permite remitirnos al escritor correntino Saturnino Muniagurria, autor de un relato policial ignoto hasta hace muy poco tiempo: "El caso de Apolonio Menéndez" (ver Pignatiello 2016). 
humor a través de la inversión: de la pregunta básica acerca de cómo adaptar una forma y unos personajes extranjeros al suelo argentino pasamos a cómo un detective local se desenvolvería en territorio británico -es decir, en un típico policial de enigma-.

Volvamos a La traducción: la presencia de Vázquez en la historia ya tenía, incluso, un episodio previo. Si en el diálogo que analizamos se hace hincapié en un problema que remite a lo estrictamente literario, en la primera aparición del uruguayo encontramos otro tema que conecta la literatura policial con la actividad del campo editorial: De Blast nos informa que Vázquez "había traducido novelas policiales para las colecciones Rastros y Cobalto" (De Santis 1998, 33). ${ }^{13}$ Podríamos interpretar la referencia a Rastros y Cobalto como una suerte de homenaje a un segmento del género policial argentino en algunas ocasiones menospreciado, en contraste con otras colecciones que gozaban de gran reputación. En efecto, Braceras, Leytour y Pittella (49-51) realizan una clasificación binaria que marca una división entre colecciones "de quiosco" y "serias": Cobalto y Rastros pertenecen a las primeras y son coetáneas de la prestigiosa El Séptimo Círculo (dirigida entre 1945 y 1956 por Borges y Bioy Casares, y posteriormente por Carlos Frías). En este sentido, podemos concebir una apuesta autoral por rescatar dos colecciones de policiales que, en tanto expresiones de la cultura popular, han sido clasificadas en franca oposición al ámbito de las letras consagradas (Braceras/Leytour/Pittella 16). Este homenaje se repite nuevamente en Los anticuarios (2010), con otra mención a Rastros y Cobalto (De Santis 2010, 128), y a la que se suma una referencia aún más amplia: "En la vidriera había unos pocos libros ajados: una novela de Somerset Maugham, La muñeca sangrienta de Gaston Leroux, unos manoseados ejemplares de la revista Leoplán" (De Santis 2010, 83). En esta cita tenemos, en una mención al pasar, varios elementos ligados a una "literatura menor": en primer término, la referencia a Somerset Maugham resulta contrastable con aquellas irónicas y descalificadoras palabras que Tomatis le dedica a Maugham en Lo imborrable (1992), de Juan José Saer: “¡Ah, Somerset Maugham! Sabía decir de sí mismo que era el primero entre los [escritores] de segundo orden, pero me parece que se juzgaba generosamente" (Saer 114). En segundo lugar, la mención a Gaston Leroux -si bien La poupée sanglante (1923) no es preci-

13. Un significativo trabajo de Campodónico facilita un panorama del mercado editorial y la literatura policial de mediados del siglo XX. También resulta relevante el trabajo de Carlos Abraham, abocado completamente a la Editorial Tor (editorial que, de hecho, es homenajeada por De Santis a través de menciones puntuales en Filosofía y Letras y Los anticuarios). 
samente una obra del género, como sí lo es su clásico Le mystère de la chambre jaune (1907)- puede ser interpretada a modo de sinécdoque de la tradición francesa de literatura policial, usualmente olvidada y desatendida en la Argentina. ${ }^{14} \mathrm{Y}$, por último, los ejemplares de la revista Leoplán nos devuelven a la reivindicación de la literatura policial "de quiosco", según la clasificación antes citada (Braceras/Leytour/Pittella 49-51).

Sin embargo, lejos de ser un homenaje solemne, vemos que la ponderación de las colecciones baratas se realiza desde una perspectiva humorística. Vázquez refiere una anécdota en que pierde en el hipódromo una novela de gángsters que debía traducir, titulada Una lagartija en la noche:

Lo llamo al editor, me dice que no tiene otra copia, y que en dos días necesita la traducción. ¿Qué dibujo lleva la tapa?, pregunto. Un enmascarado le clava un puñal a una pelirroja. La empuñadura tiene forma de lagartija. ¿Dice la contratapa dónde transcurre la acción? En Nueva York. Pasé toda la noche traduciendo el original perdido. No estuvo mal la lagartija; tuvo tres ediciones. (De Santis 1998, 33; cursiva mía)

En esta cita apreciamos otro giro humorístico que se burla del descuido en la edición de tales colecciones, con la situación extrema de una "traducción" hecha sobre un libro perdido. Pero, además, el diálogo citado se enmarca en una conversación en la que percibimos, otra vez, el desinterés de De Blast por el tema, ya que está pensando en Ana Despina: "Cuando uno está pendiente de una mujer, descuida el resto del mundo" (De Santis 1998, 34). ${ }^{15}$ De este modo, nuevamente la referencia a lo policial resulta inmersa en cierta tensión,

14. Setton sostiene la tesis de que el menosprecio de Borges por la literatura francesa determinó una configuración selectiva en la historia de la narrativa policial en Argentina: "la impugnación de la tradición francesa decimonónica ha derivado en un desconocimiento de esta rama del género y, consecuentemente, en una desatención de la literatura nacional vinculada a ella. La historia usual del género, en cambio, ha sido elaborada en gran medida a partir de la lectura de Borges -intencionadamente parcial- de los relatos de Edgar Allan Poe y de G. K. Chesterton. De este modo, un programa literario se ha transformado en la interpretación de la historia del género en la Argentina" (Setton 47).

15. La prioridad de atraer a una mujer antes que resolver una investigación es un motivo recurrente en las novelas de De Santis. El protagonista de Pesadilla para hackers (1992) lo afirma de manera muy clara: "Sé que mientras cuento esto parece como si todo el tiempo yo hubiera estado obsesionado por aclarar la razón de los ataques de locura. Bueno, en realidad eso me preocupaba, pero no estaba tan pendiente de nada como de Mariana. Creo que si fui hasta el fin fue para estar junto a ella en algo, aunque fuera peligroso y estuviera todo fuera de control" (De Santis 2015, 48). 
pues el género es traído a colación como tema de conversación, aunque al mismo tiempo el protagonista lo minimiza.

Por último, para cerrar este apartado, debemos decir que el homenaje a la "literatura menor" no implica necesariamente el desdén de la "alta literatura". Al contrario, recordemos que la primera parte de La traducción comienza con un epígrafe de Borges sobre la desconcertante tarea de la traducción. Luego, en el inicio de cada una de las restantes partes del libro, leemos epígrafes de Dante Alighieri y Ferdinand de Saussure, además de una cita de un libro apócrifo: Babel, de Ulises Drago, un autor inventado. ${ }^{16}$ Estas menciones a acendrados representantes del mundo de las letras, leídas en conjunto con las referencias de los párrafos precedentes, nos brindan una clave sobre la poética de De Santis, que se apoya tanto en expresiones de la cultura popular como en elementos literarios y teóricos más "refinados". Así, justamente, $L a$ traducción nos deja la imagen patente de que la literatura de De Santis se construye con toda la literatura.

\section{UN DETECTIVE LOCAL: LA FIGURA DEL COMISARIO}

Además de la presencia del uruguayo Vázquez y la mención que este hace de dos elementos significativos en la constitución de un policial nacional (por un lado, el problema de la traducción de una oralidad extranjera a una local y, por otro, la edición y circulación de libros policiales a través de editoriales de quiosco), en La traducción hallamos otro aspecto que nos remite a la tradición argentina de literatura policial: la figura del comisario. Según Braceras y Leytour, se trata de un personaje caracterizado por su sentido común y su sencillez, en oposición al marcado intelectualismo y la ostentosa vanidad del prototípico detective inglés. Siguiendo a estas autoras, los comisarios más conocidos son Treviranus, de Borges; Leoni, de Pérez Zelaschi; don Frutos Gómez, de Ayala Gauna; Laurenzi, de Walsh; y Baliari, de Firpo. ${ }^{17}$ Ellos "son

16. Una denominación similar, con otro nombre de pila y con una leve modificación en la acentuación del apellido, fue usada posteriormente por De Santis para el protagonista de las novelas $E l$ inventor de juegos (2003) y El juego del laberinto (2011): Iván Dragó. A su vez, el nombre de este personaje es una copia casi idéntica (con la diferencia en la tilde de la "o") de la denominación de un personaje fictivo de la cultura de masas: Iván Drago, el boxeador soviético al que se enfrenta Rocky en el film Rocky IV (1985). Si volvemos con esta mención al nombre de Ulises Drago, podríamos ver en él una sugestiva convivencia entre Ulises de Joyce y Rocky de Stallone.

17. Siguiendo a Pignatiello $(2014,108)$, podemos encontrar comisarios anteriores y posteriores a aquellos: desde el comisario del relato "La pesquisa" de Paul Groussac, de fines del siglo XIX, hasta el reciente comisario Croce, de Ricardo Piglia, que protagoniza Blanco nocturno (2010) y 
hombres sencillos que para descubrir al culpable apelan a la enorme experiencia que les ha dado el trajinar por distintas comisarías a lo largo y ancho del país" (Braceras/Leytour 19). ${ }^{18}$ En estas dos cuestiones, la experiencia y una carrera profesional que impide el sedentarismo, podemos trazar un nexo con Guimar, el comisario de La traducción. Este personaje tiene apariciones puntuales en la novela, en la medida en que se producen las muertes, y fundamentalmente hacia el final, cuando lleva consigo a De Blast por la comisaría y el museo municipal, y le explica el misterio de los lobos marinos muertos. Guimar le habla al traductor acerca de su trabajo, durante un lustro, basado en documentar todo lo que sucede en Puerto Esfinge:

-Llegué hace cinco años a este pueblo. Me dijeron que nunca pasaba nada, pero yo me di cuenta de que la diferencia entre que no pase nada y que pasen muchas cosas es una cuestión de observación. Me encontré con un archivo vacío, que fui llenando con mis propios informes, que yo redacto y que están dirigidos a mí. Desde que llegué empecé a llenar el archivo; apenas me senté compré cinta nueva para la máquina y me puse a escribir. Una carpeta para cada tema. En ese archivo está toda la historia del pueblo y nadie lo sabe. Se lo cuento a usted, porque es de afuera y porque quiero que me entienda [...]. Tengo anotado todo. A veces me sirve para presionar a la gente, pero es mucho más que eso. No quiero que nada de lo que pase quede afuera de mi archivo. No me importa que a veces no pueda actuar, que tenga las manos atadas. No sé si puedo hacer justicia y no sé si me interesa hacer justicia, pero quiero que todo quede por escrito. (De Santis 1998, 170)

En este largo fragmento tenemos varias cuestiones: en primer lugar, la observación consiste no en una práctica rutinaria del investigador, sino en una decisión política (que trae aparejada una política de la observación). Y no se trata de la observación clásica de indicios, aunque Guimar también emplea este método; al contrario, para el comisario la observación no se reduce a un mero hacer técnico, sino que implica una dimensión epistemológica, pues ella marca "la diferencia entre que no pase nada y que pasen muchas

algunos relatos incluidos en Antología personal (2014).

18. Braceras y Leytour completan la descripción con otras características: "Generalmente son provincianos y comparten con el detective clásico su condición de célibes. Suelen ser solteros o viudos, están solos, cobran un sueldo por su trabajo y no tienen familia" (19). 
cosas". ${ }^{19}$ Pero, en segundo lugar, vemos que la naturaleza curiosa de Guimar se complementa con una intención de registrar por escrito el producto de sus pesquisas -y la historia de todo el pueblo, como él mismo dice-, de modo que la observación, además de tener un fundamento político, epistemológico y una técnica de aplicación, también se proyecta hacia una operación que fije lo dicho. ${ }^{20}$ Esta actividad reviste a Guimar de una mayor elevación intelectual respecto al linaje de comisarios en que lo inscribimos; pensemos, por ejemplo, en los relatos de Walsh que tienen como protagonista al comisario Laurenzi: sus historias nos llegan a través del periodista Daniel Hernández, que es el letrado. Al contrario, en La traducción, Guimar observa y él mismo escribe el producto de su trabajo investigativo. Una vez que De Blast le refiere la historia de las muertes de Valner, Rina y Zúñiga, el comisario saca una carpeta, escribe en ella "Lengua del Aqueronte" y consulta al traductor si está bien escrito. ${ }^{21}$ Sin embargo, y en tercer lugar, en el fragmento citado hallamos otro elemento con el que volvemos a asociar a Guimar con Laurenzi, relativo a una visión pesimista sobre la justicia: "No sé si puedo hacer justicia y no sé si me interesa hacer justicia", le dice Guimar a De Blast, en una confesión que lo aproxima al tono resignado de la voz de Laurenzi. ${ }^{22}$

19. Una postura similar hallamos en el comisario Croce, de Piglia, que le dice a Renzi: "Qué quiere decir ver algo tal cual es; no es fácil" (Piglia 2010, 142; cursiva original). Y, en general, la observación es un motivo significativo de la literatura policial: sirve como clave resolutiva de un enigma (por ejemplo, en "The Purloined Letter"), pero también resulta un elemento que otorga entidad y distinción al género. Ya en la larga disquisición sobre las capacidades analíticas al comienzo de "The Murders in the Rue Morgue", leemos: "La diferencia en el alcance de la información obtenida no radica tanto en la validez de la inferencia como en la calidad de la observación. Lo que se necesita es saber qué observar" (Poe 471; cursiva original).

20. Previamente, en La sombra del dinosaurio (1992), también encontramos un ejemplo de la voluntad de dejar por escrito la historia de una localidad pequeña (de la provincia de Chubut, en este caso). En esta novela hay un ciudadano, Santiago Marón, que es la memoria viva del pueblo, y a él "l[e] preguntamos de todo, desde los nombres de los intendentes o los párrocos de la iglesia, hasta los circos o las ferias que pasaban por aquí, o los chismes de amoríos. Todo. Y cuando hayamos terminado desgrabaremos todo este material y escribiremos la historia completa de este pueblo" (De Santis 2013, 64).

21. Hay, de hecho, una autoconciencia de Guimar sobre el propio proceso de escritura, cuando comenta en broma la forma en que lo hace: "Cuando detecto un delito lo escribo en mayúsculas; eso es todo lo que puedo definir como mi estilo literario" (De Santis 1998, 170). De todas formas, en el hecho de que pregunte cómo se escribe una palabra, queda claro que Guimar no es un letrado.

22. Por ejemplo, en el cuento "En defensa propia", Laurenzi le confiesa a Hernández su incapacidad para cumplir con su deber en el final de su carrera: "Yo, a lo último, no servía para comisario" (Walsh 2013, 279). Si bien se trata de una confesión que, en el marco de una charla en un bar, resulta dotada de un componente humorístico, tampoco por eso deja de manifestar la resignación de Laurenzi. 


\section{LOBOS MARINOS, MUERTES TERRENALES: LA SERIE NEGRA}

El énfasis en la figura de Guimar nos permite pasar a otra cuestión en la que deseamos detenernos, y en ella las palabras del comisario resultan fundamentales. Hay un misterio paralelo a la trama principal de traductores muertos: la no menos misteriosa sucesión de lobos marinos muertos. ${ }^{23}$ Esta historia solo aparece en momentos puntuales: cuando De Blast va a la playa y ve cadáveres de dichos animales y, casi al final de la novela, cuando el comisario Guimar postula su develamiento. Este lleva a De Blast al museo municipal y allí da con Lugo, a quien acusa con absoluta certeza por haber matado a los lobos marinos. En el mismo museo, el comisario encuentra una maza con la que explica la "epidemia" de los cráneos rotos de los lobos marinos -cráneos rotos que De Blast no había notado en sus caminatas por la playa-. Sin embargo, comprobamos que Lugo es solo un ejecutor que mata a tres lobos marinos a pedido de dos bomberos -Trigo y Diels- y a cambio de dinero. Él ignora los motivos, es un "pobre infeliz" (De Santis 1998, 175), según Guimar. ${ }^{24}$ De Blast le pregunta al comisario los motivos por los cuales los bomberos matan animales, y la respuesta del comisario nos brinda una resolución que trae a cuenta una historia propia de una novela de la serie negra, incrustada en una sola página de La traducción:

-Donde termina Esfinge, hay un par de calles que son territorio liberado. Garitos donde se juega a la ruleta y a las cartas y ranchos donde tres o cuatro mujeres entradas en años reciben a camioneros y a obreros del puerto. Hace diez días, uno murió en una pelea o en un ajuste de cuentas; el dueño de uno de los tugurios, borracho, tiró el cuerpo al agua cerca de la costa. Cuando se emborrachan, olvidan que no hay que tirar cuerpos cerca de la costa: vuelven. Este hombre les pidió a los bomberos que se encargaran del asunto. Cuando el muerto volvió, los bomberos se llevaron el bulto envuelto en una lona y lo enterraron lejos. Antes, mientras esperaban el regreso, inventaron lo de la epidemia

23. Si bien las series de traductores y lobos marinos muertos constituyen dos historias paralelas, en la primera lectura de la novela sospechamos una posible conexión, pues las muertes de cada serie se suceden de manera alternada y cada una de ellas totaliza cuatro víctimas.

24. El hecho de que no importe quién es el ejecutor de los crímenes es un rasgo de la serie negra. En la misma dirección, vale recordar la acertada afirmación de Sebreli, quien, al comentar la obra de Dashiell Hammett, sostiene: "No interesa saber quién apretó el gatillo sino quién pagó la bala" (228). 
para distraer: así ya no importaba que los vieran. Lo hicieron hace cinco años, antes de que yo llegara, y les salió bien. Probaron de nuevo. (De Santis $1998,175-76)^{25}$

Aquí tenemos un procedimiento habitual en las ficciones de De Santis, consistente en incorporar micro-historias a la narración principal. Aunque, en este caso, la particularidad reside en que la historia referida puede ser clasificada como propia del género negro: muertes anónimas y no esclarecidas, criminales que no pagan por sus transgresiones, bajos fondos (un prostíbulo y una casa de juego ilegal en una zona liberada en los límites de Puerto Esfinge), ajustes de cuentas, vínculos entre los marginales y la fuerza pública estatal (los bomberos). En una historia contada en veinte renglones, hay una múltiple tematización de una serie de elementos inherentes a la serie negra: el poder, el dinero, la corrupción, la violencia, el cinismo y el sexismo (Giardinelli 77-88; Piglia 1979, 7-14). Y, también, un campo léxico que le es propio: "ranchos", "ajuste de cuentas", "tugurios", "borracho", "asunto".

Si bien a De Santis se lo suele asociar, con justicia, a la vertiente clásica del policial (Gamerro 85), además de esta historia paralela sobre los lobos marinos, en sus producciones identificamos otros elementos semánticos y sintácticos que permiten trazar un vínculo con la serie negra (y con el cine negro norteamericano). ${ }^{26}$ Por ejemplo, la caracterización de Lucas Lenz como una suerte de private eye en Lucas Lenz y el Museo del Universo (1992), los golpes y los blackouts en varias novelas, como Filosofía y Letras (1998), El teatro de la memoria (2000) o El calígrafo de Voltaire (2002), los ambientes prostibularios en un extenso pasaje de Los anticuarios (2010), la estructura cinematográfica que encontramos en la mayoría de sus novelas, con asesinatos que se dan progresivamente a lo largo de las historias (y no como puntos de partida, como sucede en los policiales clásicos), o el uso habitual de la primera persona para narrar.

De este modo, y sin que resulte una lectura forzada, postulamos una interpretación de la narrativa de De Santis que contemple el aporte de la hardboiled fiction, de las figuras de Raymond Chandler y Samuel Dashiell Hammett

25. Con estas palabras de Guimar podemos efectuar una precisión respecto a la vigésimo tercera nota al pie de este trabajo: la serie de lobos marinos muertos cuenta con una víctima humana entre ellas, más allá de que públicamente es presentada como la primera muerte de un lobo marino (se trata de un asesinato previo a las observaciones de De Blast, pero que abre la serie de las muertes de los animales).

26. Respecto a una concepción del género (genre) desde una perspectiva semántica y sintáctica, ver Altman (126-29). 
como sus máximos exponentes, ${ }^{27}$ y del creciente peso que ganó en la Argentina en la década de 1970 -aunque cuenta con una producción creciente ya desde las décadas de 1950 y 1960 (Lafforgue 19)- gracias a las ficciones de Eduardo Goligorsky, Juan Carlos Martini, Osvaldo Soriano o Sergio Sinay, entre otros (Rivera 1996, 99). ${ }^{28}$ Desde luego, con esto tampoco apuntamos a adscribir La traducción, sin más, a la tradición del policial negro argentino. Pero, así como antes vimos que resulta atinado poner la novela en diálogo con los pensamientos de Walsh y Ayala Gauna de mediados del siglo XX, también podemos leer la ficción de De Santis en sintonía con la tradición nacional de literatura policial negra que cobró relevancia desde la década de 1970.

\section{LA DISPERSIÓN: LAS PARTICIPACIONES GENÉRICAS}

En los apartados anteriores hemos expuesto tres grandes líneas argumentativas, cada una de las cuales permite ligar La traducción a distintas tradiciones de la literatura policial: la clásica o inglesa, la nacional y la serie negra o norteamericana. Así, la conclusión evidente es que hay un uso complejo del policial, una evocación a una multiplicidad de elementos, y no una mera pertenencia genérica.

En una concepción del género como simple pertenencia, y que podemos llamar reduccionista -aunque cualquier clasificación tienda a serlo-, ubicamos los encasillamientos de Gamerro, que incluye a La traducción en una lista de libros inscriptos en la vertiente clásica del policial (85), y de Hernando, que la aproxima a la novela negra (129). Ninguna de estas dos clasificaciones ahonda en algo más que su simple mención, y por ende su justificación está ausente,

27. Si bien muchas veces se menciona a Chandler y Dashiell Hammett como los creadores de la vertiente negra de la literatura policial, recordemos que existe un consenso respecto al carácter inaugural que tiene el cuento "The False Burton Combs", de Carroll John Daly: "The birth of hard-boiled detective literature might fairly be traced to Black Mask, and more specifically to its December, 1922, issue. That issue contained Carroll John Daly's first story, 'The False Burton Combs,' and the first crime story of Dashiell Hammett (writing as Peter Collinson) 'The Road Home'” (Yarbrough 2151).

28. Rivera, en la pequeña referencia biográfica sobre Goligorsky incluida en El Relato Policial en la Argentina: antología crítica, dice que la novela Lloro a mis muertos (1960) apareció originalmente con el seudónimo de James Alistair $(1999,135)$. Desde luego, podemos conectar en este sentido a Goligorsky y a otros "escritores fantasmas", como Roger Ivnness (Roger Pla), Pedro Pago (David Viñas), W. I. Eisen (Isaac Aisemberg) o Knut Welhaven (Guillermo Saccomanno), con la figura del uruguayo Vázquez, que se sumaría a ellos con su ya citada "traducción" de la novela fictiva Una lagartija en la noche. De esta forma, la propia presencia de Vázquez en la novela puede ser interpretada como una maniobra restitutiva de una tradición argentina de "escritores fantasmas" de literatura policial. 
pero esto es perfectamente razonable si consideramos que ninguno de los dos estudios citados tiene a La traducción como centro de sus respectivos análisis.

Resulta curioso que el propio De Santis, en una entrevista brindada a Wieser, declara otro punto de vista: ni clásica ni negra, se encarga de cuestionar el propio carácter policial de la novela y afirma que, en su opinión, es más pertinente catalogarla como literatura fantástica, pues

la resolución del enigma pasa por esa lengua extraña que lleva al suicidio. Tiene todo el clima del policial: un escenario cerrado, sólo que la resolución es fantástica. Y son los finales los que definen los géneros siempre, nunca los principios. Sólo en el catorceavo verso se sabe si un poema es un soneto; sólo si confirmamos que todo terminó bien, sabemos que hemos visto una comedia (Wieser 70-71).

Como vemos, De Santis distingue elementos que definen un clima policial (menciona el escenario cerrado, tema que desarrollamos en el primer apartado). Sin embargo, advierte un alejamiento de este género y reconoce una aproximación al fantástico, que se concreta en el final de la novela, cuando entendemos que Naum y el resto de los traductores fallecidos a lo largo de la historia mueren en el intento de hablar ese idioma diabólico y mortal: la lengua del Aqueronte.

Pero, lejos de chocar contra nuestros argumentos, creemos que la postura de De Santis los sostiene y complementa. En nuestra exposición no afirmamos en ningún momento que La traducción se trate de un mero policial (clásico o negro). Frente a la idea del encasillamiento y la pertenencia, optamos por una perspectiva que enfatice las participaciones genéricas, siguiendo la línea trazada por Derrida (10). ${ }^{29} \mathrm{Y}$, a raíz de tal concepción, resulta sensato y completamente factible que un texto tome elementos de diversas matrices y que distintos géneros se hagan un lugar en él. En el caso particular de De Santis, se trata de un autor que trabaja fundamentalmente con elementos del género policial y del fantástico, y en este sentido consideramos que La traducción es una buena síntesis de su proyecto narrativo, pues combina ambos. Con

29. Asimismo, resulta productiva la conceptualización de Heidmann y Adam sobre los efectos de genericidad, pues esta perspectiva permite concebir el vínculo de un texto con categorías genéricas abiertas (Heidmann/Adam 62). También es significativa la teoría semántica, sintáctica y pragmática de Altman sobre el género (126-29), ya citada en otra nota al pie, así como su visión dinámica del proceso de generificación (95-102). 
dicho trasfondo teórico, en este artículo estudiamos distintas modalidades a través de las cuales La traducción usa, evoca y se aproxima al género policial. ${ }^{30}$ De esta forma, logramos un doble resultado: evitar la reducción de la novela de De Santis y la del concepto de género. Así como el significante que da título a La traducción tiende a la dispersión, un análisis de los usos del policial que ella contiene nos guía por el mismo itinerario.

\section{OBRAS CITADAS}

Abraham, Carlos. La editorial Tor: medio siglo de libros populares. Buenos Aires: Tren en Movimiento, 2012.

Altman, Rick. Los géneros cinematográficos. Barcelona: Paidós, 2000.

Ayala Gauna, Velmiro. "Intención”. Los casos de Don Frutos Gómez. Buenos Aires: Huemul, 1979. 43-46.

Borges, Jorge Luis. "El escritor argentino y la tradición". Discusión. Madrid: Alianza, 1997. 188-203.

Braceras, Elena, Cristina Leytour y Susana Pittella. "Introducción: la literatura policial y su inserción en el campo de la literatura popular"; "Tipología del relato policial: novela de enigma, novela de suspenso, novela negra. Historia del género en la Argentina". El cuento policial argentino. Buenos Aires: Plus Ultra, 1986. 9-54.

Braceras, Elena, y Cristina Leytour. "Introducción”. Cuentos con detectives y comisarios: antología. Buenos Aires: Colihue, 1998. 11-23.

Campodónico, Raúl Horacio. "Los volúmenes proyectados: industria editorial y cine policial en Argentina (1941-1956)". Ficciones policiales argentinas (1870-2015): la literatura en la literatura, la bistorieta, el cine y la televisión. Comp. Román Setton. Buenos Aires: Godot, 2016. (sin pp.) [En prensa]

30. La relación con el género policial, además, coloca a La traducción en una línea sucesoria más general con el sistema literario argentino, que según Lafforgue se estructura raigalmente en el policial (11). El propio Lafforgue (21) nos recuerda, por cierto, que el vínculo de los escritores argentinos con este género no suele ser directo, sino estratégico y/o evocativo: "Por estas latitudes [argentinas] no hay escritores que escriban en y sólo en el género, pero sí hay muchos -Borges, Walsh, Piglia, Martini, Feinmann- en que las voces del policial, sus énfasis y sus tretas, se dejan oír más allá de sus textos estrictamente policiales; y hay otros -Roberto Arlt, Adolfo Bioy Casares, Antonio Di Benedetto, Bernardo Kordon, Juan José Saer- en cuyos textos pueden detectarse elementos ciertos del género, aunque lo hayan practicado muy ocasionalmente" (cursiva original). 
Cook, Michael. Narratives of Enclosure in Detective Fiction: The Locked Room Mystery. Basingstoke: Palgrave-MacMillan, 2011.

De Santis, Pablo. La traducción. Buenos Aires: Planeta, 1998.

De Santis, Pablo. Las plantas carnívoras. Buenos Aires: Aguilar/Altea/Taurus/ Alfaguara, 2006.

De Santis, Pablo. Los anticuarios. Buenos Aires: Planeta, 2010.

De Santis, Pablo. La sombra del dinosaurio. Buenos Aires: Colihue, 2013.

De Santis, Pablo. Pesadilla para hackers. Buenos Aires: Colihue, 2015.

Derrida, Jacques. "La loi du genre". Glyph 7 (1980): 1-26.

Gamerro, Carlos. "Para una reformulación del género policial argentino". El nacimiento de la literatura argentina y otros ensayos. Buenos Aires: Norma, 2006. 79-91.

Giardinelli, Mempo. El género negro: orígenes y evolución de la literatura policial y su influencia en Latinoamérica. Buenos Aires: Capital Intelectual, 2013.

Guiñazú, María Cristina. "La intriga policial como trompe l'oeil en las novelas de Pablo de Santis". ConNotas: Revista de crítica y teoría literarias 4/5 (2005): 51-64.

Heidmann, Ute, y Jean-Michel Adam. "Des genres à la généricité: L'example des contes (Perrault et les Grimm)". Langages 153 (2004): 62-72.

Hernando, Bernardino. "Traducción y periodismo o el doble y misterioso escepticismo". Estudios sobre el Mensaje Periodístico 5 (1999): 129-41.

Jacovkis, Natalia. "Latin American Crime Fiction". Critical Insigtbs: Crime and Detective Fiction. Ed. Rebecca Martin. Ipswich (Massachusetts): EBSCO Publishing, 2013. 115-29.

Konstantinova, Iana. "Detectives, Secret Societies, and Translators: The Mysteries of La traducción by Pablo De Santis". Monographic Review/Revista Monográfica 22 (2006): 196-206.

Konstantinova, Iana. "Borgesian Texts, Murders, and Labyrinths in Filosofía y Letras by Pablo De Santis”. Variaciones Borges 29 (2010): 161-76.

Kracauer, Siegfried. La novela policial: un tratado filosófico. Buenos Aires: Paidós, 2010.

Lafforgue, Jorge. "Prólogo". Cuentos Policiales Argentinos. Buenos Aires: Aguilar/Altea/Taurus/Alfaguara, 1997. 9-22.

Narváez, Adriana. "Para entrar en tema". Pablo De Santis. La traducción (Edición con guía de lectura). Buenos Aires: Planeta, 2006. 7-10.

Néspolo, Jimena "Escrituras parasitarias: el factor Borges en cuatro novísimos narradores argentinos (Jorge Consiglio, Marcelo Damiani, Pablo 
De Santis, Marcos Herrera)". Boletín de Reseñas Bibliográficas 9/10 (2007): 153-62.

Piglia, Ricardo. "Introducción". Cuentos de la serie negra. Comp. Ricardo Piglia. Buenos Aires: Centro Editor de América Latina, 1979.

Piglia, Ricardo. Blanco nocturno. Buenos Aires: Anagrama, 2010.

Pignatiello, Gerardo. "Rol policial y estructura del género en la 'novela negra' de la dictadura: Nadie nada nunca y Luna caliente". Philologie im Netz 70 (2014): 107-18.

Pignatiello, Gerardo. "Un policial correntino olvidado: El caso de Apolonio Menéndez de Saturnino Muniagurria". Ficciones policiales argentinas (18702015): la literatura en la literatura, la bistorieta, el cine y la televisión. Comp. Román Setton. Buenos Aires: Godot, 2016. (sin pp.) [En prensa]

Poe, Edgar Allan. "Los asesinatos de la Rue Morgue". Cuentos Completos I. Buenos Aires: Colihue, 2010. 467-512.

Prieto, Adolfo. El discurso criollista en la formación de la Argentina moderna. Buenos Aires: Siglo XXI, 2006.

Punter, David, y Glennis Byron. "The Haunted Castle". The Gothic. Oxford: Blackwell Publishing, 2004. 259-62.

Requeni, Antonio. "Prólogo". Pablo De Santis. Los signos. Buenos Aires: Editorial La Página, 2004. 5-6.

Rivera, Jorge B. "Introducción al relato policial en la Argentina". Jorge Lafforgue y Jorge B. Rivera. Asesinos de papel: ensayos sobre narrativa policial. Buenos Aires: Colihue, 1996. 83-104.

Rivera, Jorge B. El Relato Policial en la Argentina: antología crítica. Buenos Aires: Editorial Universitaria de Buenos Aires (EUDEBA), 1999.

Saer, Juan José. Lo imborrable. Buenos Aires: Seix Barral, 2003.

Saítta, Sylvia. "Un thriller académico". Trespuntos 105 (1999): 74.

Sebreli, Juan José. "Dashiell Hammett o la ambigüedad". Escritos sobre escritos, ciudades bajo ciudades. Buenos Aires: Sudamericana, 1997. 223-33.

Setton, Román. Los orígenes de la narrativa policial en la Argentina: recepción y transformación de modelos genéricos alemanes, franceses e ingleses. Madrid: Iberoamericana/Frankfurt am Main:Veuvert, 2012.

Waleis, Raúl. La buella del crimen. Buenos Aires: Adriana Hidalgo, 2009.

Walsh, Rodolfo. "Noticia". Diez cuentos policiales argentinos. Comp. Rodolfo Walsh. Buenos Aires: Hachette, 1953. 7-8.

Walsh, Rodolfo. Cuentos completos. Buenos Aires: Ediciones de la Flor, 2013. Wieser, Doris. "Pablo De Santis (Argentina): 'La inteligencia exagerada 
termina convertida en tontería'”. Crímenes y sus autores intelectuales: entrevistas a escritores del género policial en América Latina y África lusófona. Göttingen: GOEDOC-Dokumenten-und Publikationsserver der GeorgAugust-Universität, 2012. 66-82.

Yarbrough, Scott. "Hard-Boiled Detectives". Critical Survey of Mystery and Detective Fiction. Ed. Carl Rollyson. Pasadena (California): Salem Press, 2008. 2149-58. 